\title{
Load transfer approach for the geotechnical analysis of energy piles in a group with slab
}

\author{
Elena Ravera ${ }^{1, *}$, Melis Sutman ${ }^{1}$, and Lyesse Laloui ${ }^{1}$ \\ ${ }^{1}$ EPFL, Laboratory of Soil Mechanics, Station 18, CH 1015 Lausanne, Switzerland
}

\begin{abstract}
Thermally induced group effects characterise closely spaced energy piles. It has been observed experimentally that the behaviour of energy piles subjected to mechanical and thermal loads, in which the piles are located sufficiently close to each other, is different from the behaviour of single isolated piles. Therefore, civil engineers encounter new challenges in the geotechnical design of such foundations. This leads to the necessity to develop practical tools to address their analysis and design. The conventional load transfer method is one of the commonly used methods for the analysis of axially loaded conventional piles. Thus, the purpose of this study has been to propose a formulation of the load transfer method to consider the thermally induced effects among energy piles in groups. The soil response is characterized in a lumped form by ascribing the behavioural features of the soil to interface elements. The individual response, in terms of strain and stress of an energy pile in a group, can be addressed for the first time through the application of the displacement factor in the load displacement curve of the single isolated energy pile. A validation through a full-scale field test reveals the capability of the approach to provide the necessary information in the analysis and design phases of the foundation for one-way thermal loads.
\end{abstract}

\section{Introduction}

The load transfer method was first proposed by Coyle \& Reese [1] to address the analysis of axially mechanically loaded single piles. The main feature of the method is that the continuity of the soil domain is ignored and the pile-soil interaction is represented by springs. Each of these springs is characterised by a constitutive law. Thus, soil non-homogeneity, non-linearity, post-peak softening and interface dilation or contraction may be incorporated [2]. Over the years the need to have procedures for the design of pile foundations has led to studies focusing on the formulation of the method to consider group effects [3-6].

To date, energy piles are an expanding technology that represents an important contribution to the transition to nearly zero energy buildings. Therefore, civil engineers are asked to perform the geotechnical design of such foundations [7]. For single energy pile the load transfer approach has been modified to analyse the response to thermal loads [8-11]. The method is considered an effective analysis approach to address the energy pile capacity and deformation caused by axial mechanical and thermal loads [12]. The goal of this study is to propose a formulation of the load transfer method to consider the thermal and mechanical interactions among energy piles in group. The proposed approach provides information of paramount importance for engineering applications such as the vertical displacement, the vertical stress and the mobilised shaft resistance. The validation of the method has been performed through a heating-only full-scale field test.

\section{Load transfer method for energy pile groups}

The analysis approach considered in this study draws on the formulation of the load transfer method originally proposed by Coyle \& Reese [1]. The pile is divided into several elements. The load displacement behaviour for each of these elements is characterised at its side by an elastoplastic interaction with the soil. The element at the head and at the base are respectively characterised by an elastic pile-structure interaction and an elastoplastic interaction with the soil. An illustration of the approach is shown in Figure 1.

In dealing with the analysis of an energy pile in a group, the formulation of load displacement curves must be properly modified to consider mechanical and thermal interactions. The displacement of a pile in the group is amplified compared to that of the isolated pile due to the interactions among the piles. Therefore, an amplification factor is defined $[13,14,15]$. For energy piles this factor is called the displacement ratio, $R_{d}[15]$, to consider the displacements in both directions and it is the ratio between the average displacement of pile group and the displacement of single pile subjected to the same average load. The load displacement curves are modified according to the concept that for a pile in a group the

\footnotetext{
* Corresponding author: elena.ravera@epfl.ch
} 


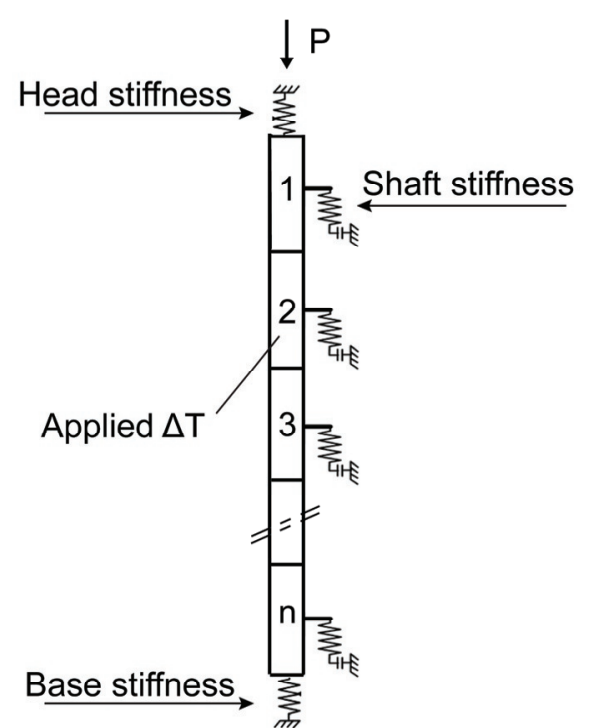

Fig. 1. Schematic of an energy pile employed in the load transfer method.

necessary displacement to mobilise the same shaft resistance of an isolated pile is multiplied by the displacement ratio and the ultimate resistance is kept the same.

$$
\begin{gathered}
w_{\mathrm{g}}=R_{\mathrm{d}} w_{\mathrm{i}} \\
t_{s, g}=t_{s}
\end{gathered}
$$

where $w_{i}$ and $w_{g}$ are the displacement of the isolated energy pile and the energy pile in group, respectively; $t_{s}$ is the mobilised shaft resistance. As for the base the load displacement curve is not modified. The load displacement curves for an isolated pile and a pile in group are shown in Figure 2. Comodromos et al. [6] introduced this approach for conventional pile groups and is employed in this work for energy pile groups.

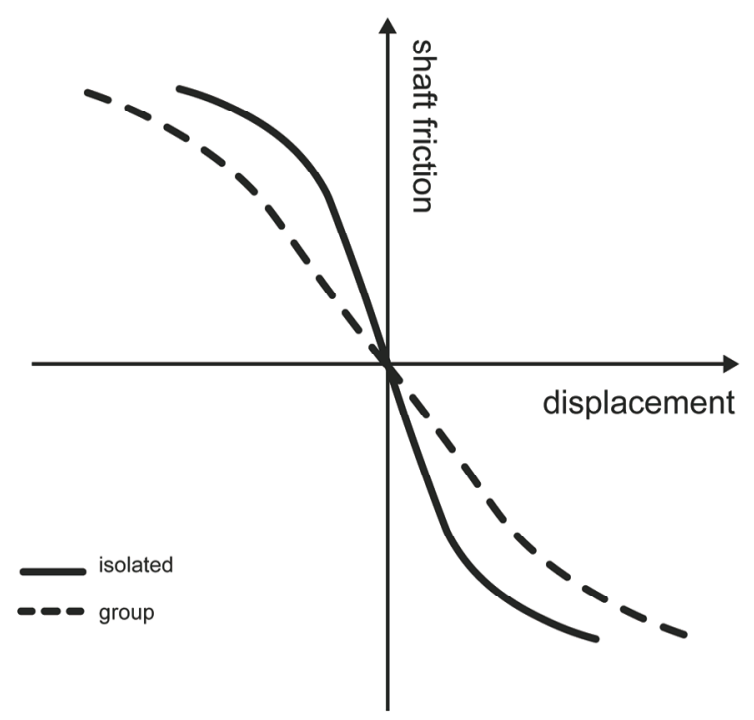

Fig. 2. Load displacement curves
When addressing the analysis of an energy pile, additional hypotheses and considerations must be introduced. In modelling the energy pile the pipes are not included, the pile material follows a linear thermo-elastic behaviour and the properties are independent from temperature changes. Investigations on the effect of the temperature on the load displacement curves [16-20] have not yet provided a solid and unified observational framework. Therefore, the ones used in this study are considered to be unaffected by temperature effects. With regards to load scenarios, the method allows an analysis towards both mechanical and thermal loads. The thermal load is idealized considering a temperature change applied uniformly and instantly along the pile. This assumption has been based on the investigations of Rotta Loria \& Laloui [21].

\subsection{Implementation of the method}

The previously described concept has been implemented in a mathematics form in a finite element code where springs have been used as boundary conditions [22]. The load displacement curves were implemented to consider a non-linear response at the interface. The laws governing the pile-soil interaction employed in this study are the ones proposed by Frank \& Zhao [23]. The equations read

$$
\begin{array}{ll}
\text { If } \quad u \leq w_{g, q_{s} / 2} & t_{s}=K_{s, g} u \\
\text { If } \quad w_{g, q_{s} / 2}<u<w_{g, q_{s}} & t_{s}=q_{s} / 2+\left(u-w_{g, q_{s} / 2}\right) K_{s, g} / 5 \\
\text { If } \quad u \geq w_{g, q_{s}} & t_{s}=q_{s}
\end{array}
$$

where $u$ is the displacement at each boundary node of the mesh. $K_{s, g}$ is the slope of the load displacement curve of the energy pile in group and represent the stiffness that govern the pile-soil interaction at the shaft; $q_{s}$ is the ultimate shaft resistance.

\section{Application and validation of the method}

The method has been applied to predict the response of an energy pile and the results have been compared with the available experimental ones [21, 24]. The results of this experiment are the reference for comparison with the results obtained using the load transfer method proposed and the resulting validation.

\subsection{Model parameters}

The model parameters are derived from the available geotechnical parameters. The site of the field test has been studied from both geological and geotechnical points of view over the years, given the construction of numerous buildings in the area. The geotechnical characterization of the area is based on laboratory tests (granulometric tests, Atterberg's limits and triaxial tests) and on-site testing (standard penetration test). In contrast to the top three layers (A, B and C), minor information relates to the molasse layer (D) for which a detailed 
geological description has been made but limited geotechnical information are available $[25,26]$. In this regard, a parametric analysis was carried out for the definition of stiffness of the springs that govern the pile-soil interaction within the molasse. The available data reflects the information that an engineer generally receives in the preliminary stages of design. This framework provides the condition to test the validity of the method under the conditions for which it is proposed (i.e. time- and cost- effective solution for the preliminary analysis and design of energy piles where limited geotechnical information is available). Therefore, the model parameters, shown in Table 1, are derived from the typical geotechnical parameters.

Table 1. Model parameters for an isolated energy pile.

\begin{tabular}{|l|c|c|c|c|c|}
\hline $\begin{array}{l}\text { Model } \\
\text { parameters }\end{array}$ & $\begin{array}{c}\boldsymbol{K}_{\text {s,i }} \\
{[\mathbf{M P a} / \mathbf{m}]}\end{array}$ & $\begin{array}{c}\boldsymbol{K}_{b, i} \\
{[\mathbf{M P a} / \mathbf{m}]}\end{array}$ & $\begin{array}{c}\boldsymbol{q}_{s} \\
{[\mathbf{k P a}]}\end{array}$ & $\begin{array}{c}\boldsymbol{q}_{b} \\
{[\mathbf{k P a}]}\end{array}$ & $\begin{array}{c}\boldsymbol{K}_{\text {slab }} \\
{[\mathbf{M P a} / \mathbf{m}]}\end{array}$ \\
\hline $\mathrm{A}^{*}$ & 6.6 & - & 7 & - & - \\
\hline $\mathrm{B}^{*}$ & 53 & - & 17 & - & - \\
\hline $\mathrm{C}^{*}$ & 57 & - & 28.9 & - & - \\
\hline $\mathrm{D}^{*}$ & $\begin{array}{c}121 \\
(242)\end{array}$ & $\begin{array}{c}667 \\
(1335)\end{array}$ & 50.8 & 15836 & - \\
\hline $\begin{array}{l}\text { Slab } \\
\text { interaction }\end{array}$ & - & - & - & - & 4449.96 \\
\hline
\end{tabular}

The model parameters necessary for the analysis of an energy pile in a group are (i) the ultimate shaft resistance, $q_{s}$, (ii) the ultimate base resistance, $q_{b}$, (iii) the slope of the elastic branch of the shaft load displacement curve $K_{s, i}$, (iv) the slope of the elastic branch of the base load displacement curve, $K_{b, i},(\mathrm{v})$ the slab stiffness, $K_{\text {slab }}$ and (vi) the displacement ratio, $R_{d}$. The ultimate shaft resistance has been estimated based on an effective stress analysis. The base resistance has been computed following the approach proposed of Zhang \& Einstein [26]. According to the description of the load displacement curves proposed by Frank \& Zhao [23], the shaft and base stiffness are determined through the Menard pressuremeter modulus. The evaluation of the head rigidity has been based on the formulation proposed by Gorbunov-Posadov \& Serebrjanyi [28]. Among the parameters the key ones for the application of the method is the displacement ratio, $R_{d}$. In this study the expression presented by Comodromos et al. [6] is recognized valid to consider the displacements among energy piles. Indeed, this expression depends on the pile group configuration and the variation in the displacement field of the single pile. In the analysis the $R_{d}$ values have been computed at each simulation step due to its dependency on the associated displacement field.

Table 2. Displacement ratio values

\begin{tabular}{|l|c|c|c|}
\hline Displacement ratio & $\boldsymbol{R}_{\boldsymbol{d}, \boldsymbol{m e c}}$ & $\begin{array}{c}\boldsymbol{R}_{\boldsymbol{d}, \boldsymbol{m e c}+\boldsymbol{t} \boldsymbol{h}} \\
\left(\boldsymbol{\Delta} \boldsymbol{T}=\mathbf{5}^{\circ} \mathbf{C}\right)\end{array}$ & $\begin{array}{c}\boldsymbol{R}_{\boldsymbol{d}, \boldsymbol{m e c}+\boldsymbol{t} \boldsymbol{h}} \\
\left(\boldsymbol{\Delta T}=\mathbf{1 0}^{\circ} \mathbf{C}\right)\end{array}$ \\
\hline$K_{b, i}=667[\mathrm{MPa} / \mathrm{m}]$ & 3.26 & 3.33 & 3.13 \\
\hline$K_{b, i}=1335[\mathrm{MPa} / \mathrm{m}]$ & 3.26 & 3.32 & 3.12 \\
\hline
\end{tabular}

It is also known that the displacement factor, $R_{d}$, must be corrected to consider the influence of the location of the pile on the behaviour of the pile in the group. In this study, since the group consists of four piles there is no dependence of the position and the location factor is therefore defined equal to unity.

\section{Results and discussion}

The case presented here refers to the condition in which all the piles are activated simultaneously.

The analysed pile has been subjected to a value of mechanical load of $495 \mathrm{kN}$ and to a thermal load of $\Delta \mathrm{T}=$ $5,10{ }^{\circ} \mathrm{C}$. These conditions correspond to the load to which each pile was subjected in the tested group [12, 24].

Figures 3, 4 and 5 show profiles of strain, stress and mobilised shaft resistance where the results obtained from the application of the proposed method are compared to the experimental ones. The presented values correspond to the variations due to the simulation of the geothermal function of the energy foundation. Thus, stresses and deformations caused by mechanical actions are not included.

Thermally induced group effects have been observed experimentally by Rotta Loria \& Laloui [24]. The highlighted effects result in an increase in strain and a reduction in stress when the pile subjected to a thermal load is in a group of piles. The experimental values shown here refer to the behaviour in the group.

Simulations with the proposed method are presented for two sets of parameters, as discussed in the Model parameters section, referring to the definition of the coefficient of interaction with the molasse layer for which limited geotechnical information was available. The maximum observed differences between the two analyses are in the order of $10-12 \%$.

The trend in terms of both deformations and stress is captured by the method. The major differences between the experimental and numerical results are both for stress and strain in the initial phase of the test (i.e., $\Delta \mathrm{T}=5{ }^{\circ} \mathrm{C}$ Figure 3(a) and 4(a)). In the experimental campaign conducted by Rotta Loria \& Laloui [21, 24] temperature measurements outline an uneven profile along the length of the tested piles while a mean value of temperature is applied constantly and instantaneously in the model. The differences can then be attributed to these differences in temperature. In fact, as the test progresses the temperature along the pile becomes more uniform and this results in a better agreement between the experimental and numerical results. From the experimental results it was possible to infer the mobilised shaft resistance. The comparison shows that the values obtained from the model predict well the experimental results. The ability of the proposed method to provide information on stress and mobilised shaft resistance profiles is an added value being the only one of the simplified methods currently available to provide such information. 


Vertical strain variations
$\Delta \overline{\varepsilon \varepsilon}$
Cxperimental
Computed $-\mathrm{K}_{\mathrm{b}, \mathrm{i}}=667 \mathrm{MPa} / \mathrm{m}$
Computed $-\mathrm{K}_{\mathrm{b}, \mathrm{i}}=1335 \mathrm{MPa} / \mathrm{m}$

(a)

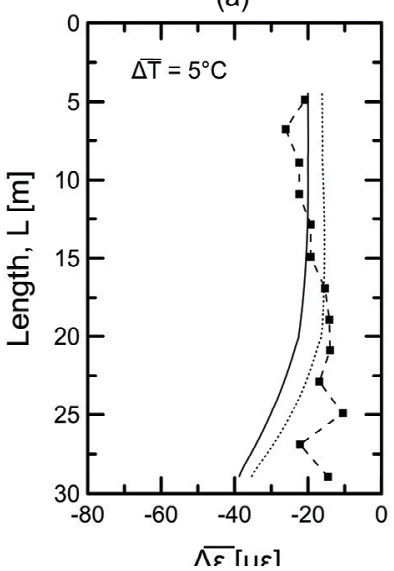

(b)

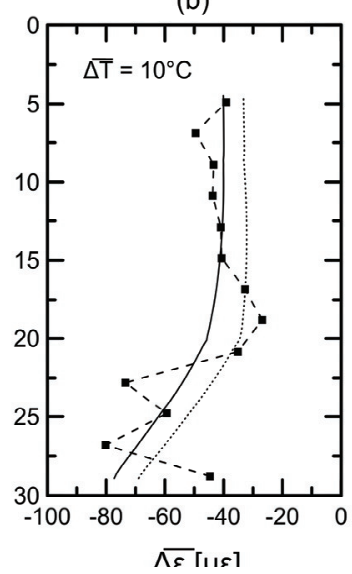

Fig. 3. Experimental and numerical vertical strain variations (a)

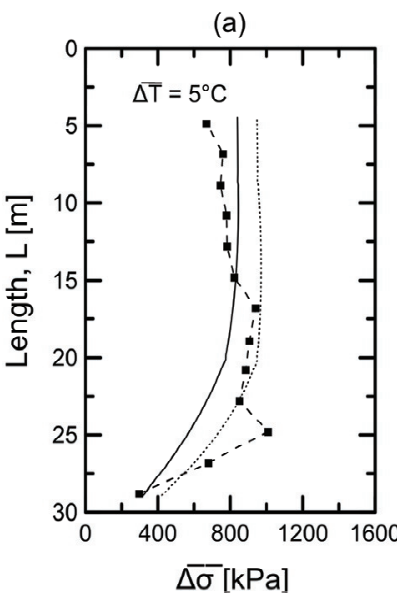

(b)

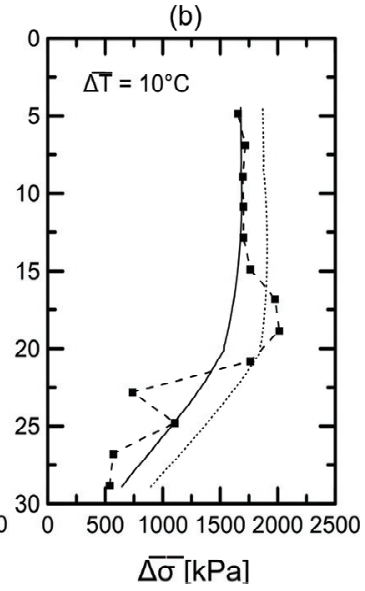

Fig. 4. Experimental and numerical vertical stress variations

\section{Conclusion}

In this study, a simplified method was presented which allows to estimate quantities of paramount importance for engineering applications such as the vertical displacement, vertical stress and mobilised shaft resistance of an energy pile in group subjected to thermo-mechanical load. The procedure for applying the method can be summarized in four steps:

1. The parameters of pile-soil interaction are defined for the case of the isolated energy pile.

2. As the field of displacement of the isolated pile is known, the displacement ratio, $R_{d}$ is determined.

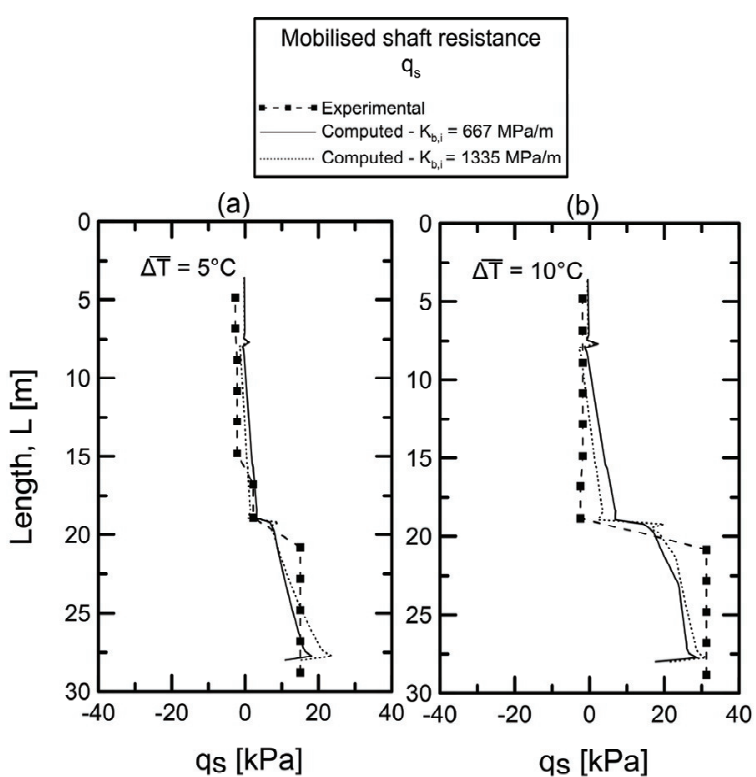

Fig. 5. Experimental and numerical mobilised shaft resistance

3. The load displacement curves of the energy pile in group is modified as explained in section 2 .

4. The analysis of the pile in the group can be conducted in the same way as those of the isolated case using the load displacement curves modified.

The presented results confirm that, despite theoretical simplifications, the pile behaviour in the group is in close agreement with the experimental data. As a general conclusion, the method proposed in this study is capable of predicting the magnitude of the vertical displacement, stress and mobilised shaft resistance of an energy pile within the group with reasonable accuracy for practical application and is therefore considered a time- and costeffective solution in the preliminary stages of design. However, it should be borne in mind that this method is classified as a simplified method and therefore has simplified hypotheses. The main assumptions relate (i) the continuity of the soil is ignored and the pile interaction is represented in a lumped form, (ii) thermal volume response of the ground is neglected, (iii) heat transfer processes are not considered and the application of the thermal load consists of applying a constant and uniform temperature variation along the entire length of the pile, (iv) the load displacement curves and pile properties are independent of temperature changes, (v) the current validated results refer to heating thermal load and conditions in which the behaviour of the pile is governed by thermally induced pile deformations.

This work was supported by the Swiss National Science Foundation (financial support N. 200021_175500, Division II).

\section{References}

1. H.M. Coyle, L.C Reese. Load transfer for axially loaded piles in clay. J. Soil Mech. Found. Div. ASCE. 92, No. 2, 1-26. (1966) 
2. H.G. Poulos. Pile behaviour-theory and application. Géotechnique 39, No. 3, 365-415. (1989)

3. M.F. Randolph, P. Clancy. Efficient design of piled rafts. 5th International Conference on Deep Foundations on Bored and Auger Piles, 1-4 June, Ghent, Belgium, pp. 119-130. (1993)

4. M.F. Randolph. Design methods for pile groups and piled rafts". State of the Art Report, XIII ICSMFE, New Delhi, vol. 5, pp. 61-82. (1994)

5. K.M. Lee, Z.R. Xiao. A simplified nonlinear approach for pile group settlement analysis in multilayered soils. Can. Geotech. J. 38, No. 5, 1063-1080. (2001)

6. E.M. Comodromos, M.C. Papadopoulou, L. Laloui. Contribution to the design methodologies of piled raft foundations under combined loadings. Can. Geotech. J. 53, No. 4, 559-577. (2016)

7. E. Ravera, M. Sutman, L. Laloui. Analysis of the interaction factor method for energy pile groups with slab. Comput. Geotech. 119, 103294. (2020) doi.org/10.1016/j.compgeo.2019.103294.

8. C. Knellwolf, H. Peron, L. Laloui. Geotechnical analysis of heat exchanger piles. J. Geotech. Geoenviron. Engng. 137, No 10, 890-902. (2011)

9. M. Suryatriyastuti, H. Mroueh, S. Burlon. A load transfer approach for studying the cyclic behavior of thermo-active piles. Comput. Geotech. 55, 378-391. (2014)

10. C. Pasten, J.C. Santamarina. Thermally induced long-term displacement of thermoactive piles. J. Geotech. Geoenviron. Engng. 140, No. 5, 06014003. (2014)

11. M. Sutman, G. Olgun, L. Laloui. Cyclic LoadTransfer Approach for the Analysis of Energy Piles J. Geotech. Geoenviron. Eng. 145, No. 1, 04018101. (2019)

12. L. Laloui, A.F. Rotta Loria. Analysis and Design of Energy Geostructures. Theoretical Essentials and Practical Application. (Academic Press, 1096 pages, ISBN : 9780128206232, 2019)

13. H.G. Poulos. Analysis of the settlement of pile groups. Géotechnique 18, No 4, 449-471. (1968)

14. H.G. Poulos, E.H. Davis. Pile foundation analysis and design. Wiley. (1980)

15. A.F. Rotta Loria, L. Laloui. The interaction factor method for energy pile groups. Comput. Geotech. 80, 121-137. (2016)

16. J.S. McCartney, J.E. Rosenberg. Impact of heat exchange on side shear in thermo-active foundations. In Proceedings of geo-frontiers: advances in geotechnical engineering (eds J. Han and D. E. Alzamora), GSP 211, pp. 488-498. Reston, VA, USA: American Society of Civil Engineers (ASCE). (2011)

17. B. Wang, A. Bouazza, C. Haberfield. Preliminary observations from laboratory scale model geothermal pile subjected to thermal-mechanical loading. In Proceedings of geo-frontiers 2011: advances in geotechnical engineering (eds J. Han andD. E. Alzamora), GSP 211, pp. 430-439. Reston, VA, USA: American Society of Civil Engineers (ASCE). (2011)

18. J.III Goode, M. Zhang, J.S. McCartney. Centrifuge modeling of energy foundations in sand. In ICPMG2014 - physical modelling in geotechnics (eds C. Gaudin and D.White), pp. 729-736. Boca Raton, FL, USA: CRC Press. (2014)

19. C.A. Kramer, P. Basu. Performance of a model geothermal pile in sand. In Proceedings of 8th international conference on physical modelling in geotechnics (eds C. Gaudin and D. White), pp. 771777. Boca Raton, FL, USA: CRC Press. (2014)

20. C.W.W. Ng, C. Shi, A. Gunawan, L. Laloui, H. Liu. Centrifuge modelling of heating effects on energy pile performance in saturated sand. Can. Geotech. J. 52, No. 8, 1045-1057. (2015)

21. A.F. Rotta Loria, L. Laloui. Thermally induced group effects among energy piles. Géotechnique 67, No 5, 374-393. (2017)

22. E. Ravera, M. Sutman, L. Laloui. Load transfer method for energy piles in a group with pile-soilslab-pile interaction. J. Geotech. Geoenviron. Eng. 146, No. 6, 04020042. (2020) doi.org/10.1061/(ASCE)GT.1943-5606.0002258

23. R. Frank, S. Zhao. Estimation par les paramètres pressiométriques de l'enfoncement sous charge axiale de pieux forés dans des sols fins. Bull. de Liaison des Laboratoire des Ponts et Chaussées 119, 17-24. (1982)

24. A.F. Rotta Loria, L. Laloui. Group action caused by various operating energy piles. Géotechnique 68 , No 9, 834-841. (2018)

25. L. Laloui, M. Moreni, G. Steinmann, A. Fromentin, D. Pahud. Test en conditions réelles du comportement statique d'un pieu soumis a des sollicitations thermomecaniques. Rapport final, Office federal de I'energie, Bern, Suisse. (1999)

26. L. Laloui, M. Moreni, L. Vulliet. Comportement d'un pieu bi-fonction, fondation et échangeur de chaleur. Can. Geotech. J. 40, No. 2, 388-402. (2003)

27. L. Zhang, H.H. Einstein. End bearing capacity of drilled shafts in rock. J. Geotech. Geoenviron 124, No 7, 574-584. (1998)

28. M.I. Gorbunov-Posadov, R.V. Serebrjanyi. Design of structures on elastic foundation. In 5th International conference on Soil Mechanics and Foundation Engineering.), vol. 1, pp. 643-648. (1961) 